\title{
VACOP-B Regimen
}

National Cancer Institute

\section{Source}

National Cancer Institute. VACOP-B Regimen. NCI Thesaurus. Code C11343.

A chemotherapy combination consisting of bleomycin, cyclophosphamide, doxorubicin, etoposide, prednisone and vincristine that can be used for the treatment of non-Hodgkin lymphoma (NHL). 